\title{
Establishment of New Facilities for WWVL and WWVB
}

\author{
John M. Richardson
}

\author{
Contribution from Radio Standards Laboratory, National Bureau of Standards, Boulder, Colo.
}

(November 4, 1963)

A brief report of the new facilities for standard radio broadeast stations WWVL and WWVB is appropriate here for two reasons. First, the organizers of the Symposium on the Ionospheric Propagation of VLF Radio Waves, to which this issue is devoted, graciously allocated a session of the Symposium for the dedication of the new stations. The characteristics and accuracy of these broadcasts are of clear interest as a tool in VLF and LF propagation research. Secondly, in this first issue of the new journal, Radio Science, it is pleasant to stress an example where radio propagation activities and radio standards activities combine so nicely to fall under the broader term, radio science.

The dedication of these facilities to the public service was made by A. V. Astin, Director of the National Bureau of Standards. An address, "The Present Status of National Standards for the Basic Physical Quantities," by R. D. Huntoon was part of the dedication session. Technical papers descriptive of the transmitter design, the antenna design, the frequency and time control system, and the station usefulness in providing standard frequencies and times were presented, and are listed by title elsewhere in this issue.

Both stations are located near Ft. Collins, Colo. Station WWVL broadcasts at $20 \mathrm{kc} / \mathrm{s}$ with a desion objective of $50 \mathrm{kw}$ delivered to the antenna and 1.5 $\mathrm{kW}$ radiated. Station WWVB broadcasts at $60 \mathrm{kc} / \mathrm{s}$ with a design objective of $50 \mathrm{kw}$ delivered to the antenna and $10 \mathrm{kw}$ radiated. Frequency of both is normally held to within 2 parts in $10^{11}$ of the United States Frequency Standard. Deviations from the stated frequency are published for users interested in the highest possible accuracy. Frequency control is realized by a 100 mile round trip servo loop between Ft. Collins and Boulder. The carrier phases as received at Boulder are compared with the phase of the working atomic frequency standard. Error signals, from both the $20 \mathrm{kc} / \mathrm{s}$ and $60 \mathrm{kc} / \mathrm{s}$ transmissions, modulate a $50 \mathrm{Mc} / \mathrm{s} \mathrm{FM}$ telemetering transmitter at Boulder. These signals are recovered at Ft. Collins and applied to a servo-motor driven resolver at the input of each transmitter. A significant feature is that long term phase coherence of the transmissions with the atomically controlled standards at Boulder is always maintained, even through transmitter outages.

Each antenna consists of four guyed masts $400 \mathrm{ft}$ high, placed in a diamond arrangement $750 \mathrm{ft}$ wide and $1880 \mathrm{ft}$ long. An insulated network of aluminum cables is suspended from each group of four masts. A down lead is suspended from the center of the cable network. The present computed radiating efficiency is 2.2 percent at $20 \mathrm{kc} / \mathrm{s}$ and 24.6 percent at $60 \mathrm{kc} / \mathrm{s}$.

The operating schedule is to be continuous on both frequencies except for regular maintenance periods. Station WWVL is operated on an experimental program of broadcasts to facilitate VLF propagation and timing research. Keyed carrier station identification in International Morse Code is used.

Time signals on WWVB consist of seconds pulses of 5 cycles of 1000 cycle, double-sideband amplitude modulation. On the beginning of each minute the pulse will be increased to one-quarter second and on the beginning of each hour the pulse will be threequarters of a second in duration. Modulation of $500 \mathrm{c} / \mathrm{s}$ is used to identify the station in International Morse Code.

Following the station call letters will be a letter, either $\mathrm{M}$ or $\mathrm{P}$ (standing for minus or plus), and a three digit number. This information gives the relationship of the carrier frequency to atomic frequency. For instance M 130 means that the carrier frequency is lower by 130 parts in $10^{-10}$ than the United States Frequency Standard. This "offset" is incorporated to enable clocks run by the broadcast frequency to keep time approximating Universal Time which is commonly used over the world. The number is broadcast because this figure changes nearly every year and could change more often. It serves as a reminder to the user that the full accuracy of the transmissions can only be realized with proper corrections.

The $60 \mathrm{kc} / \mathrm{s}$ signal is provided as a continental service of the National Bureau of Standards. The $20 \mathrm{kc} / \mathrm{s}$ signal is largely experimental. Both signals are now used to steer radio station WWV with negligible degradation of accuracy. 